\title{
A Study of the Strategic Initiatives and Its Effectiveness in Retaining Expatriates in the Indian Context
}

\section{Arthi $\mathbf{R}^{*}$}

Research scholar (FT), PSG Institute of Management Peelamedu, Coimbatore- 641 004, Tamil Nadu, India

\begin{abstract}
This paper explores the literature in analyzing the global trends of expatriate mobility and identifies the position of India regarding expatriatism in the global context. The paper studies the management strategies and initiatives of the Indian Government and the Corporates and their strategic effectiveness in attracting and retaining expatriate. The article also identifies the strategic pitfalls and finally proposes a better approach to strategic initiatives in the Indian context.
\end{abstract}

Keywords: Expatriate; Multinational companies; Strategy; Globalization.

\section{India versus Expats: An Introduction}

India being one among the Emerging and Growth Leading Economies (EAGLEs) is considered to be the most admired destination for the companies looking to send their employees abroad. The other countries in EAGLEs include Brazil, Turkey, China, Mexico, and Taiwan. Glowingly over a third of expat respondents living in Brazil (37\%) and a similarly high proportion in Turkey (29\%), India (26\%), China (24\%), Mexico (24\%), and Taiwan (24\%) moved abroad because their company compared with the global average of $13 \%$ sent them. More importantly $60 \%$ of the respondent expats living in India and China approved that their host country was getting superior as a place to live and work. An Expat Explorer survey revealed that the highest proportion of expats ( $60 \%$ compared to the $32 \%$ global average) have expressed a very positive point of view about living in India and China. Moreover India and China are considered to be the fastest growing economies in terms of GDP (Gross Domestic Product) and the highest percentage of expats seconded by employers live in these budding and emergent economies. With all these positive facts, both from the employer and the expats' point of view, it is imperative for India and the companies to retain the expats. Moreover, with Asia lodging the highest earning expats who are more likely to earn over $\$ 250,000$ p.a, which is roughly three times more than their counterparts in Europe (14\% compared with 5\% in Europe), India has the greatest opportunity to capitalize on expatriatism [1-4].

\section{India's Stance in Expatriates' Global Mobility Trend}

The HSBC Expat Survey considers four fundamental factors of the expat and provides a fair picture of the life of the expat around the world. The four fundamental factors include Expatriate Economics, Expatriate Experience, Raising Children Abroad, and Expatriate Expenses. First, the expat economics covers a variety of factors including expat income levels, saving and investing patterns, and the consequences of the current global financial environment to depict the expatriates' economic state around the globe. Second, expatriate experience includes degree of the easiness or complexity in which expats settle in the host country, the ability to mix into the local community, and their overall quality of life and lifestyle [5-8]. Third, raising children abroad identifies the top places for expat families in childcare and child development abroad. Fourth, expatriate expenses uncover the most cost-effective countries for expats to live depending on daily expenses.The survey findings also reveal that these higher earning expats are quick to capitalize on new opportunities and are flocking to Asia, where growth is expected to take off in the coming years, according to World Bank figures. Nearly two-thirds $(65 \%)$ of those earning over $\$ 250,000$ p.a. say they have been expats on more than one occasion. Nearly half $(47 \%)$ say they relocated to pursue new job prospects compared with the global average of $38 \%$, and close to a quarter (24\%) moved to improve their earnings compared to the global average of $20 \%$. As well as earning more, this group is also settling into the new culture. Two-thirds (66\%) found acclimatizing to the local culture easy (compared with a global average of $60 \%$ ), while more than a third (34\%) say their social life improved since moving (compared to a global average of $28 \%$ ). Next we consider the global ranking or position of India in relation to the four factors of the survey. India's rank and score is twelfth in Expatriate Economics and it reflects the expatriates' overall impression of India regarding its local economy in terms of the average of the household income, personal disposable income, and satisfaction. The Expatriate Experience rank and score represents the life experiences of expatriates in that country. Two-thirds (67\%) of this score is derived from the excellence of life score, with the left over third (33\%) uniformly divided between the ease of settling and integration scores, encapsulating a total of 29 diverse criteria from the survey. These diverse criterion of Expatriates experience include diet, health care, commute to work, opportunities for travel, accommodation, entertainment, work-life balance, opportunities for sports, working environment, social life, local shops and markets, feeling welcome at work, integrating into the community, making local friends, using the local language, local culture, enjoying local food, travel around locally, adjust to the new culture/lifestyle, set up utilities, adapt to local work culture, make friends, adapt to local weather, adapt to local food, learn the local language, find accommodation, organize healthcare, organize finances, and environment. India ranked 20th in the Expatriate Experience representing a lot of work to be done by the Indian government in this scope. The Raising Children Abroad ranks each country using a score

*Corresponding author: Arthi R, Research scholar (FT), PSG Institute of Management Peelamedu, Coimbatore-641004, Tamil Nadu, India, Tel: 91 9443233553; E-mail: krishnaveni@psgim.ac.in

Received June 29, 2015; Accepted September 28, 2015; Published October 05 2015

Citation: Arthi R (2015) A Study of the Strategic Initiatives and Its Effectiveness in Retaining Expatriates in the Indian Context. J Psychiatry 18: 332 doi:10.4172/2378-5756.1000332

Copyright: () 2015 Arthi R. This is an open-access article distributed under the terms of the Creative Commons Attribution License, which permits unrestricted use, distribution, and reproduction in any medium, provided the original author and source are credited 
that summarizes expat parents' views about raising their children in that country [9-12]. The Raising Children Abroad score is the average of the child care, education, health, and children's experience scores, covering a total of 11 diverse criterion which includes quality of child care, cost of child care, quality of education, cost of education, access to better education, health and well-being of children, better quality of life for children, confidence levels, outgoing nature, learning a new language, having a wider circle/greater diversity of friends. India ranks sixth in Raising Children Abroad. The Expatriate expenses rank and score comprises of expats' capacity to pay for a range of goods and services. 35\% of the Expat Expenses score is derived from the disposable income score, with the remaining $65 \%$ coming from the cost of everyday goods and services score. The Expatriate expenses score is used to reveal insights into the cost of living in the host country, but it is not included in the Expat Explorer overall score discussed earlier. India stands at ninth rank in the Expatriate Expenses score.

In summary, upon arrival to India, many expatriates reported that they benefited from cheaper living costs as well as finding the country a great place for bringing up a family. One of the main profits of raising a family in India is that it is cost efficient such that the cost of raising children is lower than in the home country as per the response from $44 \%$ of expatriates which is above a global average of $17 \%$ benefiting from the cheaper child care $(46 \%$ of expatriates found costs less against an average of $20 \%$ globally), and cheaper education ( $37 \%$ of expatriates found less expensive against $17 \%$ of expatriates globally). In India $54 \%$ of expats found children's education easier to organize and $75 \%$ of expatriates opt for international schooling against $40 \%$ of expats worldwide. Most expatriates in India report greater savings on daily expenses compared to home countries. Percentage of expats spending less on utilities, groceries, clothing, health care, housing, and household goods are $43 \%, 42 \%, 42 \%, 41 \%, 40 \%$, and $40 \%$ respectively. The corresponding global averages are $26 \%, 22 \%, 26 \%, 27 \%$, and $23 \%$ respectively. $40 \%$ of expats find it difficult to adapt to local work culture, $43 \%$ find a enhanced work-life balance, $39 \%$ of expats account for a healthier social life against $28 \%$, the global average and $60 \%$ find easy in making local friends against a 50\% the global average [13-16].

\section{Government of India Strategic Initiatives: An Overview India In Business: A Favoured Investment Destination}

India roughly with a growth rate of 8 percent for over a decade from 2000 has unlocked the gateways for opportunities in several sectors by attracting the interest of global institutions and investors. The economic reforms carried out by the government has emphasized on creating an investor friendly environment, which includes opening up foreign direct investment in most sectors. India with the economic reforms, bilateral and multi-lateral trade and investment agreements, and commitment to fulfillment of developmental aspirations of its people has helped in absolute association with the aim of increasing investment in the country.

\section{Indian Economy}

India as one of the world's fastest growing economies following China has recorded a decadal growth rate of 7.8 percent during FY 03FY 12. It got on this high growth trail during the Tenth Five Year Plan recording a growth rate of more than 8 percent in FY 04 reaching a summit point of $9.6 \%$ in FY 07. The growth in the Eleventh Five Year Plan also made several headlines for being the highest five year plan growth ever in India. In FY 09 there was a slowdown to $6.7 \%$ due to 2008 global economic crisis. The facilitating factors, which include a strong domestic demand, growing services sector, higher investment, a reform-focused government, and expanding infrastructure recovered Indian economy quickly. The strong fundamentals factors of India grabbed the world's attention, specifically from foreign investors which was vivid for a three-fold rise in the BSE Sensex closing at 19,610 in FY 13 against to 5,839 in FY 03.Though the Indian economy is slowing in response to today's domestic and global factors, Government of India (GoI) and the RBI undertook numerous actions in reviving growth and to instill positive sentiments between business investors and the multiparty institutions. With FY $14 \mathrm{~s}$ projected economic growth recovery India promises strong growth prospects stepping into the future. Investment and Technology Promotion (ITP) Division of the Ministry of External Affairs (MEA) published by India in Business' a comprehensive guide, providing information to business on various aspects of investing in India and profiles of 25 key sectors with sectoral trends, summary of the market conditions, key pull factors and a blueprint of investment opportunities. The investment environment in any country is dependent on the regulatory policies and procedures existing, this publication also covers the legal, administrative, and compliance aspects of Foreign Direct Investment (FDI) [17-20].

\section{Expanding Infrastructure: Key Initiatives}

- India's infrastructure has been continually improving as reflected in the following instances.

- India's domestic telecom sector, the second largest in the world, includes wireless and wired subscriber base of 867.8 million and 30.2 million by March 2013 respectively.

- The installed electricity capacity experienced a 12 percent y-o-y to 223,343.6 MW by March 2013.

- The refineries had a capacity of 215 MT by April 2013.

- In support developing infrastructure in the 12th Five Year Plan, the GoI is to realize an investment of $\$ 1$ trillion. Almost every other sector including airways, railways, and ports were expanded in supporting higher capacity. The private sector is expected to play a major role in projects from sectors such as power, airports, metrorail, and road.

- World Economic Forum's Global Competitiveness Report 2012-13 depicts that India fares well with 27/144 rankin railroad infrastructure followed 68/144 rank in airways. A continued government support would help in further expansion in infrastructure with improved rankings.

\section{Increased Government Support}

The 12th Five Year Plan aspires to launch vital reforms, larger participation of the private sector, growth of infrastructure, amplified urbanization, high literacy rate, and enrichment of administrative and labor skills. The Plan is projected with budget allocation $\$ 656$ billion from $\$ 350$ billion in the 11th Five Year Plan. The priority sectors identified in the plan cater to objectives of higher employment, better technology, strategic security, and competitive advantage in sectors such as textiles, gems and jewellery, handicrafts, electronics, IT hardware, automotive, telecom, aerospace and pharmaceuticals.

Several measures initiated by government of India (GOI) include:

- Steady decrease in subsidies on gasoline, LPG (cooking gas) cylinders and high speed diesel in an effort in reducing the fiscal deficit and line up product prices to the market;

- Dis investment in PSUs to boost government revenues; 
Citation: Arthi R (2015) A Study of the Strategic Initiatives and Its Effectiveness in Retaining Expatriates in the Indian Context. J Psychiatry 18: 332 doi:10.4172/2378-5756.1000332

- Formation of a Cabinet Committee on Investment to expedite clearance of projects with an investment of more than \$ 183.8 million;

- Relaxed FDI limits for aviation, insurance, pension broadcasting and retail sectors in an effort to improve access to sophisticated technology and create employment in addition to facilitating increased Foreign Investments (FI);

A Project Monitoring Group was formed in tracking large investments both in public and private sector projects to help speed up the commissioning of projects. India recorded a $\$ 50.2$ billion in FI for FY 13 higher than FY 11 and FY 12. The total FDI inflow accounted to $\$ 199$ billion during April 2000 to June 2013, with Mauritius, Singapore and the UK contributing a share of $58 \%$ being the three largest sources of FI for India. It is found that India's strategy aims in taking every effort to attract global attention and in improving expatriation in the country. The FDI, expanding infrastructure, future growth prospects, and challenges help in improving expat's overall experience in India.

Key amendments on Financial Act 2013

Indian Policy and expat relaxation and tax benefits include:

- Indian company is liable to pay tax @ 22.66\% on dispersed income upon buy back of its own unlisted shares w.e.f. June 1, 2013.

- Preservation of tax applicable to a non-resident taxpayer on 'royalty' and 'fees for technical services' (FTS) earned from India improved from existing rate of $10 \%$ to $25 \%$.

- Reintroduction of compulsory requirement for foreign taxpayers to offer tax residency certificates certifying its nationality to claim treaty benefits.

- Common anti-avoidance rules (GAAR) requirements postponed to be effective from FY 2015-16 onward.

- Extra investment allowance @15\% permissible for manufacturing companies on investment in plant and machinery exceeding INR 1000 million or more during the period from April 1, 2013 to March 31,2015 .

- Reduced withholding tax rate @ 5\% on foreign arrears in form of rupee-denominated bonds issued to Qualified Foreign Investor (QFI) and Foreign Institutional Investors (FII).

\section{Corporate Strategic Initiatives: Retaining Expatriates}

Understanding expatriates on international assignment and particularly to the Indian context helps in improving the strategic initiatives by the corporates and the government in retaining them. A study conducted by Jain C.D. help in understanding expats. The pictures in this section represent the results of finding from Jain.C.D experiment. The below pictures depict the characteristics of expats under different circumstances.

Reasons for an expat in refusing international assignment reflects the values or concerns of expats and by addressing them would help corporates attract and retain expats for a longer tenure. Top factors include concerns about family and spouse, followed by culture differences, followed by compensation is represented by Figures 1 and 2. Similarly the key factors for the failure of exacts include expat's inability to adapt to a new culture, unable to meet job demands, expat's

\section{Reasons given for refusing international assignments

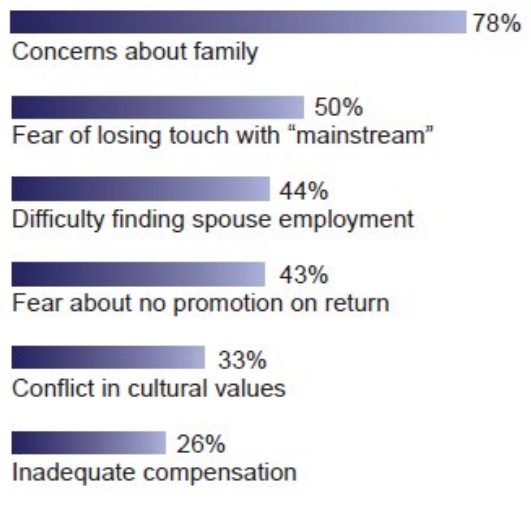 \\ Figure 1: International Assignment refusal.}

\section{Why expatriates fail internationally

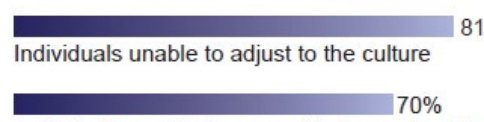 \\ Individuals unable to cope with demands of the job \\ Family unable to adjust to the culture

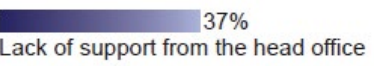

Figure 2: Expatriate failure key factors.

family's inability to adapt to new culture and finally lack of support from the head office.

Jain.C.D also found that there is a huge gap between the importance of expat factors and the comparative importance of the same factors for the Indian company. The major factors compared include relocation, compensation, family adjustment, and Indian infrastructure. Relocation and infrastructure are of concern for expats which are to be considered and addressed for better expat experience represented in Figure 3.

It is also significant to understand the characteristics of expats that differ completely from that of repatriate. It is a vivid form that Figure 4 depicts, opposing values for expats and repatriates toward adaptability, acceptance, preference, and perceived longevity. Initially accepting an offer to work and then in reality settling down and relocating the family, often turn out to be a challenging problem. Though most companies are thoughtful toward relocation but an organized approach seems missing. Remarkably, the families of returning Indians seem to have equal or more difficulties adjusting to India than expats.

Some facts regarding Indian talent arena

- In an Indian context it is the relationships that are significant than transactions. Precisely, companies managers or the recruiter does a worthy job by increasing a one-to-one connection with prospective and current employees stand a greater chance of attracting and retaining those individuals.

- A continued demand for increased compensation is normal in the Indian work force and is a part of the culture. 
Comparative importance of factors

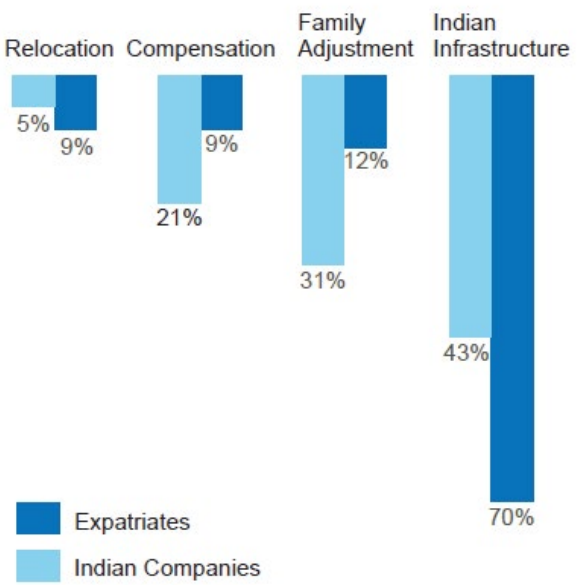

Figure 3: Relocation and infrastructure are of concern for expats which are to be considered and addressed for better expat experience.

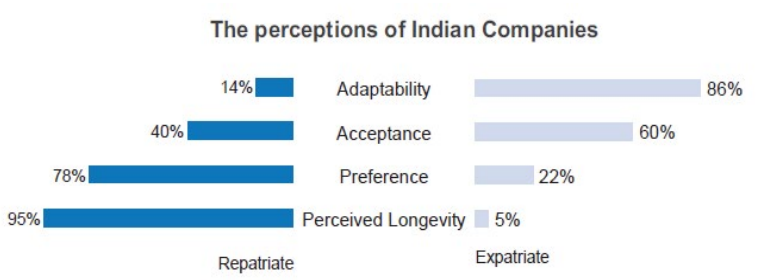

Figure 4: Perception of Indian companies over repatriate and expatriates.

- India and Asian markets should be considered for Gen X and Y workforce and corresponding policy and human resource strategy should be in place.

- The Indian talent market is basically categorized into representing Indian cities as tier 1 (metropolitan/larger), 2 , and 3 (rural/smallest) cities. Tier 2 and 3 cities represent talent as not robust and tier 1 cities such as Mumbai, Delhi, and the like, serve as the main source of efficient and ready talent.

- Much more concerned about the long-term career developments in specific terms.

- The challenge of an individual's expectation to move up the organizational ladder faster termed as "career velocity" in India is greater than in any other market.

\section{Recommendations}

\section{Expatriate compensation strategy}

Hiring and retaining the right people in the right place at the right time, while keeping the expenses low, remains the main challenge still today. Thus there is a strong trend toward reconsidering policies to adapt to varying circumstances while still accomplishing the primary goal. The result of Monique Neijzen and Sandra De Bruyker's Survey depicts an additional challenge faced by the companies: while $83 \%$ of companies assume their expatriate populations to stay the same or increase, companies are yet under burden to cut costs in various ways. $44 \%$ are considering accepting a "low cost alternative package" such as a reduced balance sheet package $56 \%$ or a host balance sheet arrangement $36 \%$. Moreover, $23 \%$ of companies are supposing an increase in the amount of training or developmental assignees willing to accept a cheap package in return for international experience enhancing their future career prospects. There are in general two approaches to expat compensation: purchasing power comparison, an approach in which an expatriate's purchasing authority is in relation to either the home or host location or the purchasing power of other expatriates and salary comparisons. The second approach considers either to match an expatriate's whole salary to home or host location standards, or setting an international salary level reference to pay all expatriates within a similar salary system. Balance sheet system (full or modified/reduced), headquarters-based system, proxy-based system, and equalized spending at the host country are some examples of purchasing power comparisons. A salary comparison comprises of the host country salary (plus), greater of home or host salary, and a regional or international salary. Unsurprisingly in practice a variety of mixed strategies exist as well. An experiment was conducted an experiment and identified the following inference regarding expat compensation. The experiment authorizes that the growth of alternative packages, including the reduced balance sheet package, the headquarters-based system, the proxy-based system, equalized host spending, the safety net, the host salary, the greater of home or host, and the international salary. Academically, the flawless system considers equity in comparison to the home location, equity among expatriate peers from diverse origins, and equity in relation to local host peers. But in reality maximizing all three types of equity is not a possibility, thus companies end up making trade-offs that highlights some needs over others. Today it is common to find most multinational companies using a mixed strategy for expatriate compensation, owing to a multiplicity of driving business motives.

\section{Expatriate centers: The key drivers of talent attraction and retention}

In the study, identified the importance of expatriate centers and their role as key drivers in talent attraction and retention. Their research included study of expatriate centers, its profile, its structure, and the range of services offered by them in four European cities: Amsterdam, Brno, Hamburg, and Vienna, and there by emphasized expatriate center's main features and best practices. Additionally the research helped in assessing the purpose of the expatriate centers in the perspective of city marketing and branding strategies. It was found that the four European expatriate centers played a significant role in improving the city image as a striking place to live and work among the highly skilled migrant community. Owing to their status as providers of relevant administrative, business, and social services, as well as enablers of information and networking events, expat centers were a high value association between the local city government and the highly skilled migrants. In the context of globalization and a knowledge economy, place marketing and branding strategies developed by local governments had the key purposes of talent attraction and retention. In-depth examination of four European expat centers illustrates that expat centers play a tremendously role in engaging highly skilled migrants toward the best city experience and in contributing to their optimistic opinion and first-hand knowledge of the location.

\section{Expats versus corporate-level international strategy: Governing with the knowledge contract}

The principal-agent problem (also known as agency dilemma or theory of agency) occur when one person or entity (the "agent") is 
able to make decisions on behalf of, or that impact, another person or entity: the "principal." The dilemma exists because sometimes the agent is motivated to act in his own best interests rather than those of the principal. Knowledge contract is defined as the governance mechanisms, or rules of the game, by which organizations monitor and reward expatriate managers for how they acquire, synthesize, and share local knowledge with the subsidiary, other subsidiaries, or the firm's headquarters. Knowledge contract is in both implicit (psychological) and explicit (written) forms, and research considers the written form. Organizational knowledge goals steers the written knowledge contract, which Yan et al. characterize in 3 constituents: retention, transfer, and utilization of expatriate manager expertise. Findings from Connelly's study conducted on Expat International Strategy governed by knowledge contract makes explicit predictions on the type of knowledge contract that is most likely to address agency problems for each of the 4 corporate-level international strategies: global, international, transnational, and multi-domestic types. The investigation encompasses agency theory by familiarizing the knowledge contract as a means of dealing with the agency concerns. This offers a broader range of contract substitutes, moving researchers beyond traditional agency theoretic medicaments. The experiment adds value to the literature on expatriate management by integrating expat assignment triumphs with the research on corporate-level international strategy thereby recognizing that the organizational strategy as a significant unit of study in international human resource management yielding a unique set of contingency relationships that would otherwise be obscured. In conclusion, the research ideas contribute to research on repatriation as well. Considerable amount of literature on expatriate assignments concerns itself with problems of selection, training, adjustment, the assignment itself, and matters prior to departure. Repatriation literature addresses adjustment back to the home country, career management, and retention. The knowledge contract embraces the potential to lighten repatriation concerns, consequently making expatriate assignments more attractive to managers. Organizations may anticipate common problems related with repatriation, such as career development and role uncertainty and fold them back into the knowledge contract to reduce managerial uncertainty regarding repatriation. Thus it positively affects expatriate managers' readiness to admit overseas assignments and their ability to accomplish international assignments.

\section{Human resource development (Hrd) strategies for expatriate development: review of current strategies and potentials for expatriate mentoring}

Kim AE on her research identified the importance of unique potentials of expatriate mentoring contributing toward expatriate growth and development in all the three stages of expatriation, preexpatriation, during expatriation on international assignments, and repatriation stages with respective training strategies which include cross-cultural training, pre-departure and post-arrival training. The research conducted also identifies the gaps in the HRD strategies for expatriate training and development, and highlights the fact that the expatriate mentoring helps in filling the gaps. By definition crosscultural training (CCT) is termed as those educative processes that are designed to promote intercultural learning, by which the acquisition of behavioral, cognitive, and affective competencies is associated with effective interaction across culture. While CCT, pre-departure and postarrival training are forms of a formal training often limited in duration and conducted in a time-constrained manner, expatriate mentoring is an informal development relationship or on-the-job, one-on-one training having a very valuable advantages and potential in filling the gaps CCT or pre-departure training or any other training leaves out and cultivates expatriates knowledge and experience. Mentoring which could occur anytime over the three phases of expatriation in the workplace, is less expensive and is much more cost-effective. Moreover with mentors form a key source of real-time learning for the expats making mentoring a significant workplace learning strategy. Global integration, local responsiveness strategy, social support mechanism, and developmental purpose are four purposes of expatriate mentoring. With global integration and local responsiveness becoming chief dimensions of international HR strategies, achieving a balance in both the strategies helps in competitive advantage for corporates. Maintaining synchronized acquaintances and network amid corporate headquarters and subsidiaries helps in achieving global integration for the corporates. Conversely, expatriation is one of the most adapted policies in achieving global integration helping in the development of expatriates, in achieving their success, and in contributing toward global integration strategies. Expatriates are in turn anticipated to mentor and coach host-personnel for effective localization.

\section{Strategic Challenges and Scope}

\section{Government of India perspective}

The return to faster growth is not automatic. The government needs to invest greater effort on several key areas. Ensuring a stable macroeconomic environment and reversing the fiscal deficit increase mounting from 2008 should be tackled first as top priority. Achieving infrastructure investments through public sources and public-private partnerships should be the second top priority considered as the singlebiggest supply-side limitation for India's growth and competitiveness. Indian energy prices are to be aligned with global prices through a gradual transition. Goods and Services Tax (GST) in indirect taxation and policy regulations and reforms for the ease of doing business are to be achieved as a part of strategic initiative. India remains an attractive destination for foreign direct investment (FDI), following the US, China, UK, and Brazil, on grounds of India's solid domestic market, workforce literacy, and globally competitive labor costs. Nevertheless, the country needs to boost its business environment by plummeting corruption and intensification of laws, expand infrastructure, increase manufacturing, simplifying taxation system, more relaxation and reform into FDI regulations, and enhance awareness about its emerging cities. Today Investors consider India for services and manufacturing supply chain, but for investments in materializing the environment must be further encouraged.

- Measures on other competitive issues, along with currency stability and business friendly environment should be fostered. The consumer products, industrials, media, telecom, and technology and life sciences sectors are set to propel India's growth over the next couple of years. India persists in drawing a healthy share of the capital allocated to rising markets.

- Potential areas of concern for Multinational Corporations (MNC's) due to recent amendments

- Transfer pricing (TP): Comprehensive TP regulations, rising number of TP audits and strict penal penalty for noncompliance with regulations result in hesitation.

- Taxation of out of the country M\&A deals: The Indian Tax Authorities have in recent past reasoned the Indian tax impact of overseas M\&A deals relating to transfer of shares of an Indian company. The matters are being severely considered for legal action. 
Citation: Arthi R (2015) A Study of the Strategic Initiatives and Its Effectiveness in Retaining Expatriates in the Indian Context. J Psychiatry 18: 332 doi:10.4172/2378-5756.1000332

Page 6 of 7

- Withholding tax: strict enforcement of withholding tax rules by Indian Tax Authorities.

- Tax withholding mandated on out of the country salary payments to expatriates working in India.

- Indian Government has lately mandated payments toward social security for "International Workers."

Tax Treaties: Direct Taxes Code to potentially override Tax Treaties entered into by India.

\section{Corporate perspective}

Major challenges and constraints moving forward by Corporate Human Resources (CHR) include. Though the supply of talent and the demand for talent would continue to increase despite a slump in economic forecasts demand norms do not match the supply characteristics. Today, MNCs increasingly demand highly skilled, highly flexible, mobile employees who can deliver the desired results, operating sometimes in difficult circumstances.

- Talent sources with domain expertise are very limited

- Importance of education in the Indian culture fosters a challenge in retaining top talent as they leave for higher education.

- Companies operating as a monopoly within will almost certainly have to bring in an expat or source from an MNC who operates within the same industry.

- Redefining expat compensation to global is a top need for Multinationals. The below figure represents Aon Hewitt's redefinition of reward strategy to global need and also lists the latest trends in globalized compensation. Figure 5 represents the three aspects of global compensation-global, local, and regional considerations found as an equal mix.

There has been a momentous change in business objectives and the rewards strategy is in compulsion toward transformation to maintain competitiveness in the global market, to ensure effective alignment with localized people strategy and costs with the business objectives.

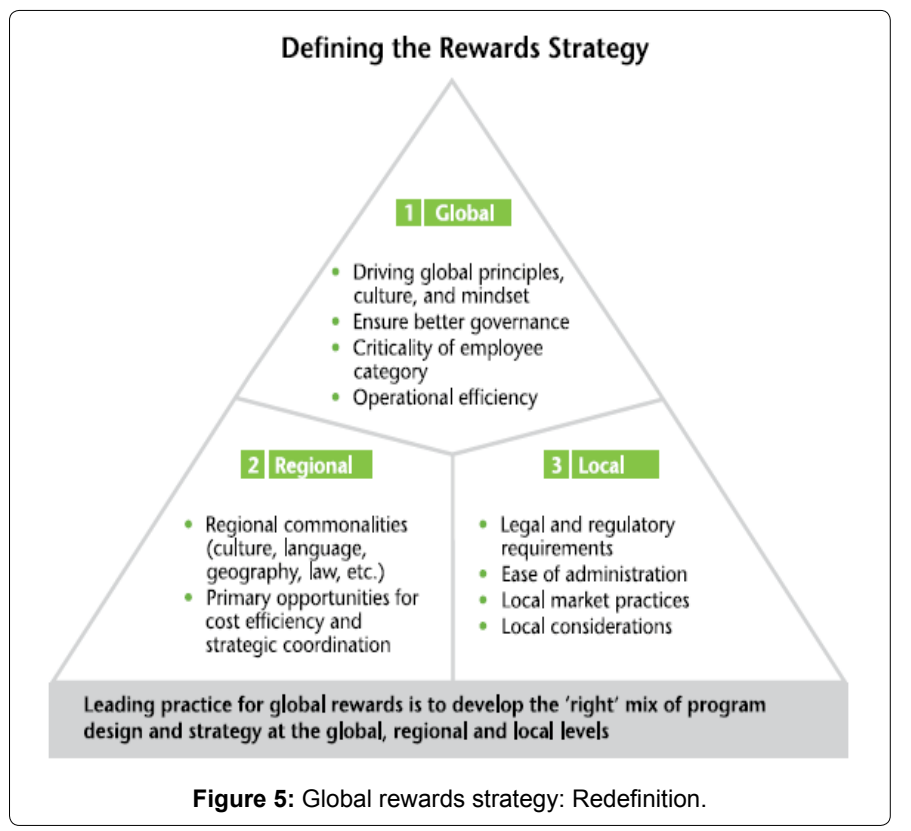

- Facilitate global mobility for the required talent.

- Ensure competitiveness of the employment.

- Offer in the new location and offer scalability.

- Treat employees comparably, irrespective of their home country

- Provide flexibility in order to balance global and local needs

- Be compliant with local requirements.

Aon Hewitt has developed a simple framework for rewards, which includes four major pillars business, workforce, culture, and strategy in defining global compensation called as the BWCS Framework.

It is also perceived that a globally significant shift is toward:

- A greater focus on differentiating and rewarding performance.

- Increased prevalence of variable pay programs.

- Importance of market competitiveness.

New tools, procedures, and management competences are required to focus in particular on the sourcing, retention, and career planning of the key talent across the corporation. This is a major challenge and opportunity for CHR managers seeking to redefine their role in a context of downsizing, restructuring, and outsourcing. CHR should identify four specific roles in Global Talent Management (GTM): champions of process, guardians of culture, network leadership and intelligence, and managers of internal receptivity. The ultimate aim of MNCs is to build a core competence of being able to transfer capability across multiple countries, which involves monitoring the implementation of relevant policies and practices, encouraging an appropriate corporate culture, establishing the necessary networks, and ensuring that all parts of the organization are sensitive to the needs of international staff. Grounded on the tendencies of increasing local sourcing necessitates a shift to a capability-driven perspective which demands a focus across the firm to contribute in communal sharing of talent and involve in joined-up thinking and action regarding GTM.

- Recruiting an army of students from universities helps in developing a group sickness helping with better retention. Individuals in groups tend to compare compensation.

- Fostering programs to reach out to the families and the employee stress the importance on the family role that is much more significant in the society.

- Stressing importance to the sense of nationalism and nationalistic sentiments help in the Indian context

- In Corporates, it is important to increase awareness of intercultural competence.

- The marketing of an organization's infrastructure helps in attracting talent.

- Importance to flexible work benefits and stress on work-life balance is as a key employment and a differentiator in attracting talent.

- Importance and respect to woman is also a key employment and a differentiator in attracting talent and helps in increased reputation of the company.

- Often India does not get leveraged as a location for executive developments since most of the time the overall corporate strategy 
Citation: Arthi R (2015) A Study of the Strategic Initiatives and Its Effectiveness in Retaining Expatriates in the Indian Context. J Psychiatry 18: 332 doi:10.4172/2378-5756.1000332

Page 7 of 7

does not reflect India's priority.

- The corporate's ability to attract top-level executive talent is determined by a combination of a company's corporate brand and its long-term operation in the country. Thus corporates require an exceptionally strong global brand if it does not have a longoperating history. Otherwise the corporates do not require a strong brand name.

- Corporates should focus more on long term, sustainable initiatives than having priority on short-term (e.g., quarterly) results was viewed as exceptional.

- Transparency and honesty of corporates help in positive reputation in the Indian talent market and it is important for corporates to recognize its needs to customize employee communication for the Indian market.

\section{Conclusion}

This paper helps in bringing together the global trends in expatriatism and benefits of India's global stance in attracting and retaining expats. The paper analyses the strategic initiatives of corporates in the Indian context, the strategic initiatives of the government of India, it identifies respective challenges and pitfalls and finally provides recommendations on a strategic perspective for better talent attraction and retention. With India yet to reach the first position or rank as the FDI preferred destination, or in expat experience, or in expat economics, there is a huge scope of improvement and progress in every aspect of expatriatism. It is imperative for India to act quickly with effective and efficient strategic decisions in attracting and retaining expats. The suggested or recommended strategies from study and analysis in this paper for immediate implementation include corporate initiatives with realignment to a global expat compensation strategy, addressing agency problems through knowledge contracts, Human Resource Development Strategies for Expatriate Development by Expatriate Mentoring, along with GOI's initiative including expansion and investment in developing infrastructure, creating and enabling expat centers in expat talent and retention, introducing more FDI friendly reforms, eliminating corruption, reducing deficits, and improving standard of living in the country with better lifestyle, education, and security. This paper could be extended as qualitative research and analysis could be performed in measuring the strategic effectiveness of recommendations proposed. Each recommended strategy could be considered for further research and development. This paper stands as a single source of reference in providing a complete coverage of expatriatism in the Indian context.

\section{References}

1. Balasubramanyam VN, Sapsford D (2007) Does India need a lot more FDI, Economic and Political weekly. 1549-1555.

2. Chadha Rajesh (2009) FDI in India and its Growth Linkages, National Council of Applied Economic Research (NCAER).

3. Choudhury SR (2009) Japan's Foreign Direct Investment Experiences in India Lessons Learnt from Firm Level Surveys, ICRIER Working Paper 243.

4. Department of Industrial Policy and Promotion (2012) FDI Synopsis on Japan Ernst \& Young (2012): Ready for Transition- 2012 Attractiveness Survey.

5. Ghosh Indranil (2007) Responding to Globalization- Japanese FDI in India, Centre for Study in International Relations and Development Discussion Paper 20.

6. Japan Bank for International Cooperation, (2008) "Survey Report on Overseas Business Operations by Japanese Manufacturing Companies".

7. JETRO White Paper on "Outward Foreign Direct Investment" Various Issues.

8. Hideki E (2001) "The Japanese Response to India's New Economic Policy", in Economic Liberalisation in India: Japanese and Indian Perspective (ed.), ICSSSR, New Delhi.

9. Hideki Y (2007) "Japanese Exports and Foreign Direct Investment: Imperfect Competition in International Markets", Cambridge University Press.

10. India Brand Equity Foundation (2010): India and Japan, Automobile Sector.

11. Iqbal BA, Ghauri FN (2011) FDI and Indian Economy: A Case of Japan FDI, Business and Management Review 1: 25- 31.

12. Japanese Bank for International Cooperation (2011) Outlook for Japanese Foreign Direct Investment, 23rd Survey.

13. Rajamohan PG, Rahut DB, Jacob JT (2008) Changing Paradigm of IndoJapan Relations: Opportunities and Challenges, ICRIER Working Paper 212.

14. Nayak KJR Amar (2005): FDI Model in Developing Economies: Case of Suzuki Motor Corporation in India, The Journal of American Academy of Business, Cambridge.

15. SIA News Letter (2010, 2011 and 2012) Government of India, New Delhi India

16. Siddharthan NS (1999) European and Japanese Affiliates in India: Difference in Conduct and Performance, Economic and Political Weekly 34: M61-M65.

17. Walsh, James P, Jiangyan Yu (2010) Determinants of Foreign Direct Investment: A Sectoral and Institutional Approach, IMF Working Paper No.187.

18. World Bank (2012) World Investment Report, Washington D.C.

19. Assignments in India-Overview of tax and regulatory framework for foreign nationals September 2014.

20. http://www.ey.com/Publication/vwLUAssets/EY-attractiveness-surveyIndia-2014/\$FILE/EY-attractiveness-survey-India-2014.pdfEY's\%20 attractiveness $\% 20$ survey, $\% 20$ India $\% 202014, \% 20$ Enabling $\% 20$ the $\% 20$ prospects, $\% 20$ www.ey.com/growing $\% 20$ beyond. 